\title{
Purification of the Insecticidal Toxin in Crystals of Bacillus thuringiensis
}

\author{
By MAUREEN LILLEY, R. N. RUFFELL AND \\ H. J. SOMERVILLE* \\ Shell Research Limited, Shell Biosciences Laboratory, Sittingbourne \\ Research Centre, Sittingbourne, Kent ME9 8 AG
}

(Received 15 October 1979)

\begin{abstract}
Crystals were purified from four serotypes of the insect pathogen Bacillus thuringiensis. Crystals from these serotypes were similar in amino acid and $N$-terminal analyses, but differed in their toxicity to two species of Lepidoptera and in their immunological properties. Toxic polypeptides were obtained following trypsin digestion of solutions of the crystals. In two strains (serotypes 3 and 9) this fraction contained only one polypeptide. Similar results were obtained when dissolved crystals were digested with other proteolytic enzymes or with gut contents from Pieris brassicae. The trypsin-resistant polypeptide was further purified by gel and ion-exchange chromatography and had a molecular weight of about 70000 , estimated by gel chromatography and gel electrophoresis. No evidence was obtained for a toxin of lower molecular weight. This purified toxin accounted for most, if not all, of the toxic activity originally present in the crystal solution and was active by injection and ingestion. The purified toxic fraction from serotype 1 appeared to contain two polypeptides, one of which corresponded to that found with serotypes 3 and 9 . There were no major differences in the composition of crystals from different serotypes of $B$. thuringiensis and it is concluded that the trypsin-resistant polypeptide represents the active insecticidal toxin of the crystal.
\end{abstract}

\section{IN TRODUCTION}

Viable preparations of Bacillus thuringiensis have been in widespread use in insect control for several years. The activity of these preparations arises from an insecticidal toxin and, probably, from pathogenic invasion of susceptible insects by the micro-organism. The toxin has been shown to be associated with the crystalline inclusion of $B$. thuringiensis, which is formed concomitantly with sporulation (see, for example, Young \& Fitz-James, 1959). The selective action of $B$. thuringiensis preparations on a wide range of lepidopterous larvae may result from the requirement for alkaline proteolytic conditions to effect dissolution of the crystal. At least two proteolytic enzymes related to trypsin and chymotrypsin have been demonstrated in gut contents from Pieris brassicae. Spores of B. thuringiensis survive exposure to gut juices (Somerville et al., 1970) and penetrate the midgut wall, which is broken down as a consequence of primary intoxication, to multiply in the haemolymph. Death can apparently result either from intoxication or from septicaemia.

Some strains of $B$. thuringiensis produce another insecticidal toxin - exotoxin - which has a wider spectrum of activity (Bond et al., 1971). The strains used commercially do not produce exotoxin and are without known harmful effects on mammals. The selective agent in the crystal is heat-labile and estimates of the molecular weight of the toxin vary over a range from 500 to over 100000 (Somerville, 1973). 
Although the strains of $B$. thuringiensis form a well-defined group which is closely related biochemically (de Barjac \& Bonnefoi, 1968) and genetically (Somerville \& Jones, 1972) to Bacillus cereus, there are strain differences in immunological properties (Krywienczyk \& Angus, 1966; Pendleton \& Morrison, 1967) and activities towards different target species of Lepidoptera (Galowalia et al., 1973). It is not known, however, whether there are major strain variations in the number or nature of the polypeptide components of the bipyramidal inclusions characteristic of the $B$. thuringiensis group. The object of this study was to compare the biochemical, immunological and toxicological properties of the toxin isolated from crystals of several representative strains of B. thuringiensis.

\section{METHODS}

Growth of cultures and preparation of crystals. Representative strains of serotypes 1,2, 3 and 9 of Bacillus thuringiensis were maintained and grown on nutrient agar (Oxoid). The medium was dispensed in Roux bottles or Petri plates and inoculated using a glass spreader. Cultures were harvested when sporulation was complete $\left(3\right.$ to $4 \mathrm{~d}$ at $30^{\circ} \mathrm{C}$ ). For serotypes 1,3 and 9 , the subsequent removal of vegetative cells and preparation of purified crystals were carried out as described previously (Delafield $e t$ al., 1968). The yield of crystals was approximately 250 to $500 \mathrm{mg} \mathrm{l}^{-1}$ of nutrient agar culture and about $20 \%$ of the dry weight of the initial spore/crystal mixture. For serotype 2, prolonged sonication and isopycnic centrifugation were used to obtain preparations of comparative purity (Somerville et al., 1972). With this strain insufficient material was obtained to carry out detailed studies.

Dissolution of crystal protein and digestion by proteases. Crystals were dissolved in a modification (Norris, 1969) of the buffer used by Ellis (1961). This reagent (reducing buffer) contained the following (final concentrations): $\mathrm{Na}_{2} \mathrm{CO}_{3}, 50 \mathrm{mM}$; 2-amino-2-methylpropane-1,3-diol, $50 \mathrm{~mm} ; \mathrm{NaH}_{2} \mathrm{PO}_{4}, 50 \mathrm{~mm}$; citric acid, $50 \mathrm{~mm}$; 2-mercaptoethanol, $100 \mathrm{~mm}$. The 2-mercaptoethanol was added and the $\mathrm{pH}$ adjusted to 10.5 with $\mathrm{NaOH}$ before making up to volume. The 2-mercaptoethanol was replaced by dithiothreitol in some experiments; $0.15 \mathrm{M}-\mathrm{NaOH}$ (alkali) and $8 \mathrm{M}$-urea/1\%(v/v) 2-mercaptoethanol, pH 8.5 (urea/mercaptoethanol) were also used where indicated.

A crystal suspension of known protein concentration was added to at least 10 volumes of reducing buffer and left at room temperature for $1 \mathrm{~h}$. The resulting clear solution was then centrifuged at $1000 \mathrm{~g}$ for $10 \mathrm{~min}$ and, where indicated, the clear supernatant was dialysed overnight at $4{ }^{\circ} \mathrm{C}$ against $1 \mathrm{~mm}-\mathrm{NaHCO}_{3}$.

Crystal solutions were digested $\left(18^{\circ} \mathrm{C}\right.$ for $\left.3 \mathrm{~h}\right)$ by various proteolytic enzymes at $\mathrm{pH} 10.0$ in an autotitrator (Radiometer, Copenhagen, Denmark) using $5 \mathrm{~mm}-\mathrm{NaOH}$ to maintain the $\mathrm{pH}$ and with $5 \%(\mathrm{w} / \mathrm{v}$, with respect to the crystal protein) of the digesting enzyme.

Chromatography. Sephadex G-200 or G-100 (10 g, Pharmacia) was suspended in reducing buffer with $10 \mathrm{~mm}$-2-mercaptoethanol and heated at 60 to $80^{\circ} \mathrm{C}$ for 5 to $6 \mathrm{~h}$ before packing the columns, which were eluted with two or three column volumes of reducing buffer (10 $\mathrm{mM}$-2-mercaptoethanol) before application of the sample. All separations were carried out at $4{ }^{\circ} \mathrm{C}$ and the Sephadex columns were calibrated with proteins of known molecular weight (Andrews, 1965). The exclusion limits for both Sephadex G-100 and G-200 were lower in reducing buffer than in $1 \mathrm{~mm}-\mathrm{NaHCO}_{3}$.

Pre-swollen DEAE-cellulose (Whatman DE 52) was stirred gently in reducing buffer ( $\mathrm{pH} 5 \cdot 5$, without 2-mercaptoethanol). The material was degassed and equilibrated with reducing buffer at $\mathrm{pH} 10 \cdot 2$ containing $10 \mathrm{~mm}$-2-mercaptoethanol. The protein sample was applied to the bottom of the column $(20 \mathrm{~cm} \times 1.6 \mathrm{~cm}$ diam.) using a peristaltic pump. Reducing buffer $(50 \mathrm{ml})$ was passed through before applying a linear gradient of 0 to $0 \cdot 5 \mathrm{M}-\left(\mathrm{NH}_{4}\right)_{2} \mathrm{CO}_{3}\left(50 \mathrm{ml} \mathrm{h}{ }^{-1}\right)$.

Sephadex A-50 (Pharmacia) was prepared and packed as for Sephadex G-200. Two bed volumes of reducing buffer (10 mM-2-mercaptoethanol) were passed through the column before applying the protein sample to the top, followed immediately by approximately $50 \mathrm{ml}$ of starting buffer. A linear gradient of 0 to $0.5 \mathrm{M}-\left(\mathrm{NH}_{4}\right)_{2} \mathrm{CO}_{3}$ was then applied $\left(15 \mathrm{ml} \mathrm{h}^{-1}\right)$.

Peak protein fractions were pooled and concentrated for disc gel electrophoresis or further chromatography by ultrafiltration using an Amicon apparatus with a type UM2 membrane. Protein samples for analysis were dialysed against $1 \mathrm{mM}-\mathrm{Na}_{2} \mathrm{CO}_{3}$ buffer, $\mathrm{pH} 10$, and stored at $4{ }^{\circ} \mathrm{C}$.

Amino acid analysis. In most cases, the Sanger (1949) procedure was used for $\mathrm{N}$-terminal determination. The DNP-amino acids were separated by thin-layer chromatography (Eastman Kodak 6061 plates) using a sequential two-dimensional system of solvents, chloroform/methanol/acetic acid (95:5:1, by vol.) followed by chloroform/tert-amyl alcohol/acetic acid (70:30:3, by vol.). In some cases, spores were eluted by suspending in $0 \cdot 15 \mathrm{M}-\mathrm{NaHCO}_{3}$ and recovery was estimated spectrophotometrically. In a few experiments, the 
Edman procedure (Edman \& Sjoquist, 1956) was used. Insulin was used as a control with 70 to $100 \%$ recovery of DNP-phenylalanine and DNP-glycine by the Sanger procedure.

Enzymic digestion with carboxypeptidase $(4 \%, \mathrm{w} / \mathrm{w}$, protein) was carried out in $0.1 \mathrm{M}$-bicarbonate buffer, pH 8.0 , at $25^{\circ} \mathrm{C}$. Protein was removed by centrifugation after addition of ethanol and the supernatants were analysed for amino acids by thin-layer chromatography on cellulose using propan-2-ol/formic acid/distilled water (40:2:10; by vol.). Quantitative amino acid analyses were carried out as described above with controls of carboxypeptidase and test polypeptide alone.

Immunological methods. Crude rabbit antisera to crystal solutions were prepared as described previously (Delafield et al., 1968). ${ }^{125}$ I-labelled antibodies were purified by the procedure of Freedman et al. (1966). The assay was carried out using the method described by Grant \& Simon (1968).

Gel electrophoresis. Electrophoresis in polyacrylamide gels containing $0 \cdot 1 \%(\mathrm{w} / \mathrm{v})$ sodium dodecyl sulphate (SDS) (Shapiro et al., 1967) was used as modified by Herbert et al. (1971) to include 4 M-urea in the gel. Standard proteins (bovine serum albumin, cytochrome $c$ and trypsin) were run in order to establish the relationship between mobility and molecular weight (Weber \& Osborne, 1969). Absorbance measurements of stained gels were made by scanning the gels at $620 \mathrm{~nm}$ using a Gilford 240 spectrophotometer.

Bioassay by ingestion. Toxicity was measured by the inhibition of feeding of larvae of Pieris brassicae or Trichoplusia ni or, in one case, Plutella maculipennis. Protein solutions or suspensions of known concentration were serially diluted in $0.002 \%(\mathrm{v} / \mathrm{v})$ Triton X-100 in water. Leaf discs $(4.7 \mathrm{~cm}$ diam.), cut from smooth leaves of Brassica oleracea (cabbage, var. Flowers of Spring), were dipped in solutions of toxin, drained, air dried and then placed in Petri dishes $(4.8 \mathrm{~cm}$ internal diam.) containing six larvae (third instar). Untreated leaves and leaves treated with Triton X-100 were used as controls. After $24 \mathrm{~h}$ at $21^{\circ} \mathrm{C}$ in an illuminated room, the area of leaf eaten was measured with a photodensitometer calibrated to read in percentage of leaf area. Assays were carried out in duplicate and, except where described in the text, a linear graph of the logarithm of concentration of protein $\left(\mu \mathrm{g} \mathrm{ml}^{-1}\right)$ versus leaf eaten was drawn and the concentration of protein $\left(\mu \mathrm{g} \mathrm{ml}^{-1}\right)$ required for $50 \%$ inhibition of feeding $\left(\mathrm{LC}_{50}\right)$ was obtained. Results were expressed in $\mathrm{LC}_{50}$ values or in units calculated with a standard preparation $\left(1000\right.$ toxic units $\left.\mathrm{mg}^{-1}\right)$ of $B$. thuringiensis, known as E61, as a control. For comparison with injection bioassays, smaller leaf discs $(0.5 \mathrm{~cm}$ diam.) were coated with measured samples of the test solution, air dried and fed to larvae before assaying, as above, with untreated leaf discs.

Bioassay by injection. Protein solutions for assay by injection were serially diluted in $10 \mathrm{~mm}$-sodium phosphate buffer, $\mathrm{pH} \mathrm{8.0}$. Fifth instar larvae of Pieris brassicae were immobilized by anaesthetizing with $\mathrm{CO}_{2}$ and were then injected $(5 \mu \mathrm{l})$ into the haemocoel using an Arnold hand microapplicator, attached to a $1 \mathrm{ml}$ syringe, with a $26 \mathrm{~g}$ needle. The larvae were placed in Petri plates containing discs of cabbage leaf $(4.7 \mathrm{~cm}$ diam.). After $24 \mathrm{~h}$, the inhibition of feeding was measured as described above. Control larvae were injected with $5 \mu 110 \mathrm{~mm}$-sodium phosphate buffer, $\mathrm{pH} 8 \cdot 0$.

Protein determinations. Protein was estimated using the Lowry procedure with crystalline bovine serum albumin as a standard.

Chemicals. 'AnalaR' grade components of media, buffers, etc., and chymotrypsin were obtained from BDH; specialized media components were from Oxoid; 2-mercaptoethanol, papain and ficin were from Sigma; pronase and trypsin were from Boehringer; and pepsin was from Koch-Light.

Regurgitated gut contents from fourth and fifth instar larvae of Pieris brassicae were obtained by stroking the larvae against the rim of a $14 \times 100 \mathrm{~mm}$ test tube and then frozen until required. After thawing, the gut contents were centrifuged $\left(6000 \mathrm{~g}, 18^{\circ} \mathrm{C}, 15 \mathrm{~min}\right)$ to remove any debris.

Antiserum was from Dr B. N. Herbert.

\section{RESULTS}

\section{Digestion of dissolved crystals}

SDS-gel electrophoresis of samples removed at various times during trypsin digestion of a solution of crystals from serotype 9 showed a rapid disappearance of higher molecular weight polypeptides (Fig. 1). The bands of molecular weight $>240000$ were not detected at any time after addition of the enzyme. This disappearance of high molecular weight material was accompanied by the appearance of new bands with molecular weights in the approximate range of 70000 to 240000 . As digestion progressed, these and other bands disappeared, with the exception of a band (A, in Fig. 1) corresponding to the original band of lowest molecular weight, and some lightly stained material (indicated by the brace) of 

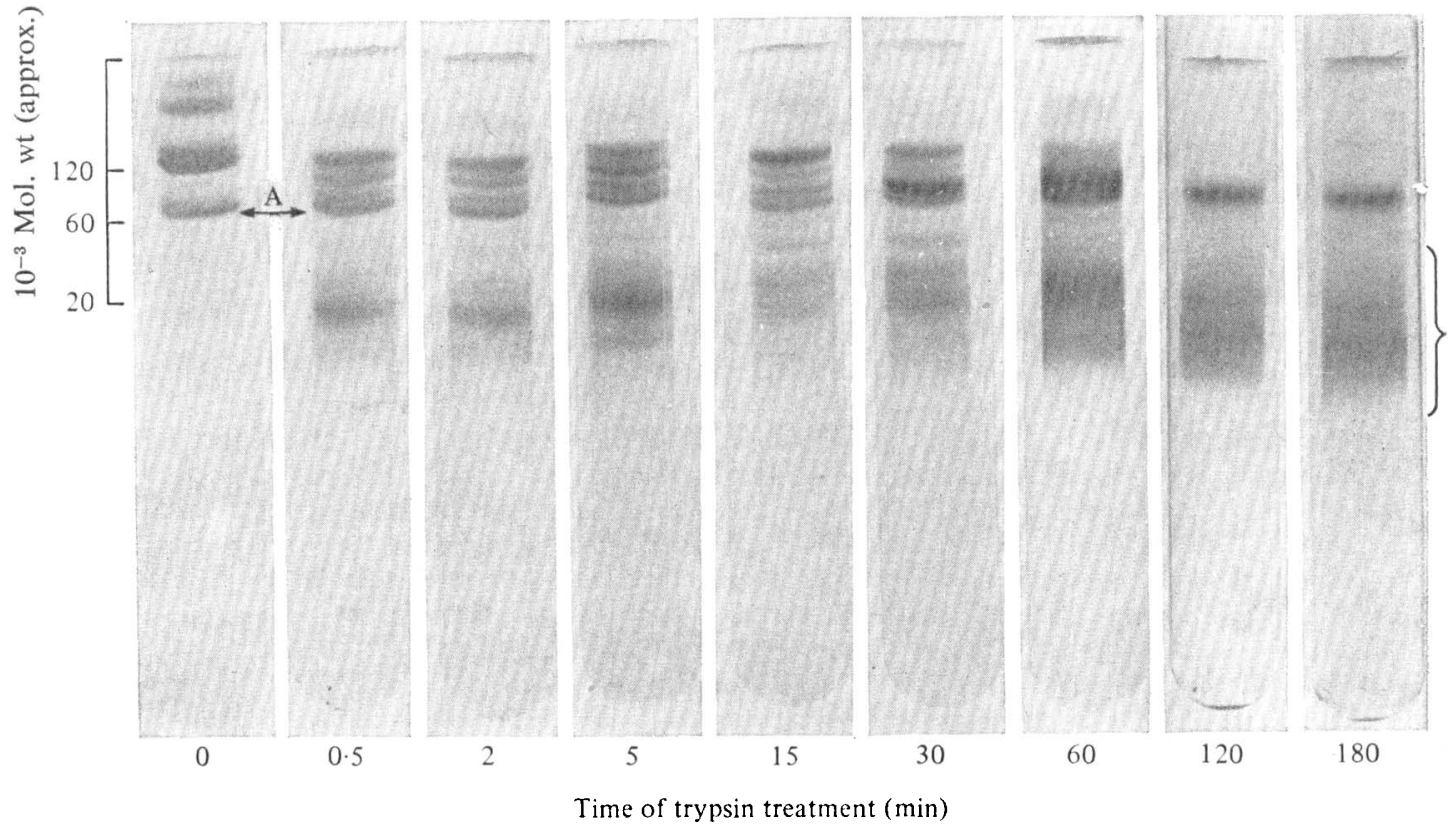

Time of trypsin treatment $(\mathrm{min})$

Fig. 1. Effect of trypsin on polypeptide components of crystal solution (serotype 9). Crystal solution $\left(5 \mathrm{mg} \mathrm{ml}^{-1}\right)$ was digested with trypsin $\left(0.25 \mathrm{mg} \mathrm{m}^{-1}\right)$ at $\mathrm{pH} 10$ for $3 \mathrm{~h}$. At the times indicated, samples $(0.2 \mathrm{ml})$ were withdrawn and soybean trypsin inhibitor $(50 \mu \mathrm{g})$ was added to stop the reaction. Samples $(0 \cdot 1 \mathrm{ml})$ were then examined by SDS-gel electrophoresis. The brace at the right indicates polypeptides formed as a result of digestion (see text). The undigested crystal component referred to in the text is indicated by $\mathrm{A}$.

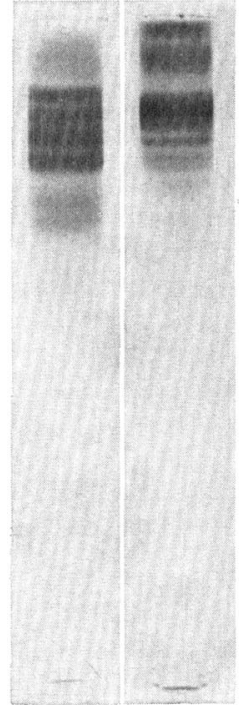

$1 \mathrm{~A}$

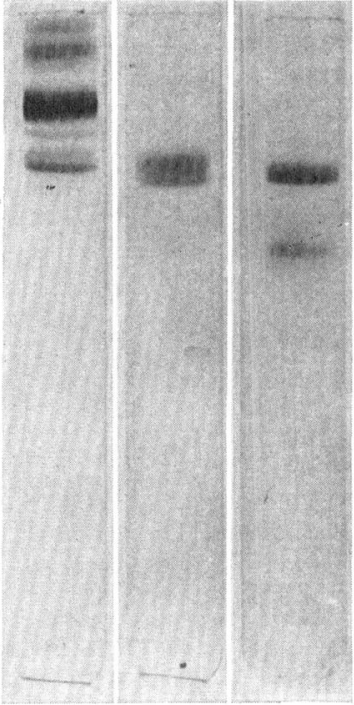

$1 \mathrm{~B}$

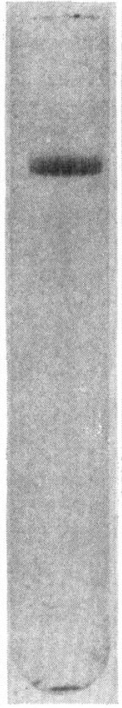

9B

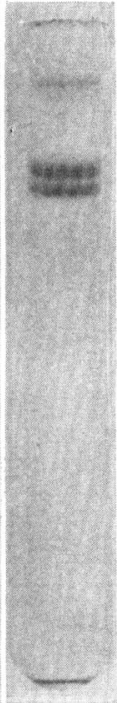

$1 \mathrm{C}$

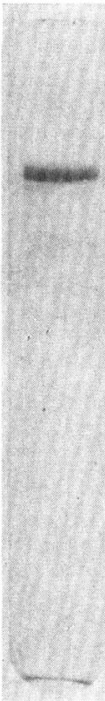

$3 \mathrm{C}$

$9 \mathrm{C}$

Fig. 2. Effect of trypsin digestion on polypeptide components of solutions of crystals from serotypes 1,3 and 9 . Crystal solution $\left(5 \mathrm{mg} \mathrm{m}^{-1}\right)$ was digested with trypsin $\left(0.25 \mathrm{mg} \mathrm{ml}^{-1}\right)$ at $\mathrm{pH} 10$ for $3 \mathrm{~h}$. Samples were examined by SDS-gel electrophoresis. The serotypes are indicated by number: A, crystal solution; B, trypsin digest; $\mathrm{C}$, purified toxin after elution from DEAE-cellulose. 


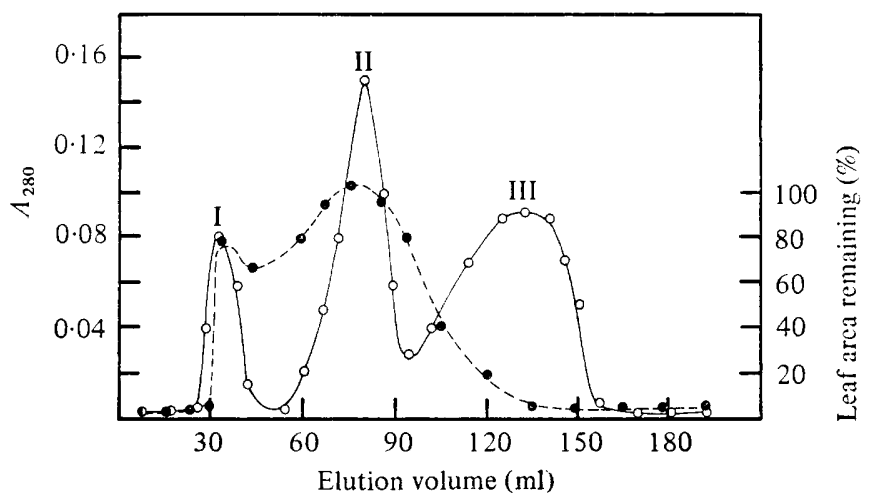

Fig. 3. Gel filtration of trypsin digest of crystal solution (serotype 9). Dissolved protein was digested for $3 \mathrm{~h}$ as described in the legend to Fig. 1 and $20 \mathrm{mg}$ protein was eluted from a column $(40 \times 2 \cdot 6 \mathrm{~cm})$ of Sephadex G-200 with reducing buffer. Eluted protein, measured as $A_{280}(\bigcirc)$; inhibition of feeding of Pieris brassicae larvae (O).

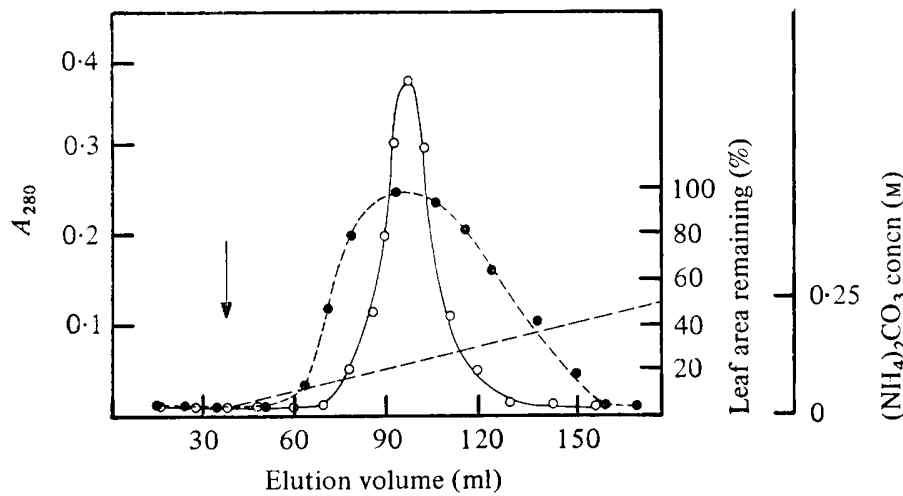

Fig. 4. Chromatography of partially purified toxin on Sephadex A-50. The pooled fractions in peak II from gel filtration (Fig. 3) were concentrated and eluted from a column $(20 \times 1.6 \mathrm{~cm})$ of Sephadex A-50 with a gradient of 0 to $0.25 \mathrm{M}-\left(\mathrm{NH}_{4}\right)_{2} \mathrm{CO}_{3}$ in reducing buffer (the arrow indicates the start of gradient elution). Eluted protein, measured as $A_{\varepsilon_{80}}(\bigcirc)$; inhibition of feeding of Pieris brassicae larvae (O); $\left(\mathrm{NH}_{4}\right)_{2} \mathrm{CO}_{3}$ concentration (- - ).

lower molecular weight which presumably consisted of fragments formed from the larger polypeptides. Densitometer scans of gels from the same amount of digest at different times showed that the amount of A was constant through the digestion.

Digestion of crystal solutions with pronase, papain, ficin, collagenase, chymotrypsin, or gut contents from Pieris brassicae gave similar results to those with trypsin, both with respect to patterns on SDS-gel electrophoresis and elution profiles from Sephadex. In each case, A was the only component of the digest with a molecular weight in the range of the components of the crystal solution. This component was isolated as purified toxin using the procedures described below.

Digestion by trypsin of solutions of crystals from serotypes 1 and 3 followed a similar pattern to that obtained with serotype 9 . In each case, the polypeptides of molecular weight $>70000$ disappeared (Fig. 2). However, with material from serotype 1, two polypeptides with similar molecular weights (60000 to 70000) remained. Further prolonged digestion with trypsin, chymotrypsin or larval gut contents did not remove either of these bands or the single band from serotype 3 . 


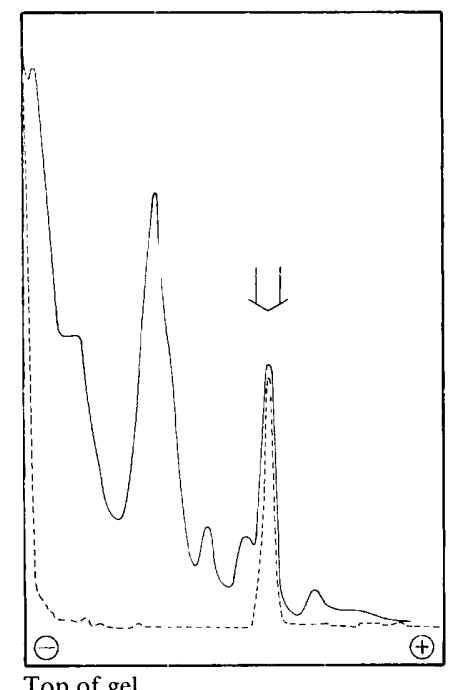

Fig. 5. Densitometer scans of gels of crystal solution and purified toxin. Samples of crystal solution and purified toxin from serotype 9 were examined by SDS-gel electrophoresis. The arrow indicates the relative position of bovine serum albumin (monomer). Crystal solution (-); purified toxin after elution from Sephadex A-50 (- - -).

\section{Fractionation of digested crystal solution}

The solution of crystals of serotype 3 is excluded from Sephadex G-100 (Delafield et al., 1968) and this was confirmed with serotype 9 . However, fractionation of the digest of serotype 9 crystal solution on Sephadex G-100 or G-200 produced three fractions (Fig. 3). Toxicity to Pieris brassicae was associated only with the first two peaks. These were eluted with the void volume (I) and at an elution volume corresponding to a molecular weight of about 70000 (II). The toxicity of some fractions in peak II is underestimated, as complete, or close to complete, inhibition of feeding was observed and estimation of the $\mathrm{LC}_{50}$ using dilutions of each fraction would have revealed a more pronounced peak of toxicity. The proportion of the total material in peak I could be controlled, to some extent, by varying the amount of trypsin added or the time of digestion.

SDS-gel electrophoresis of the material in peak II revealed one major component although minor bands were also evident. Further purification was achieved by ion-exchange chromatography on Sephadex A-50 or DEAE-cellulose. One major peak was found which eluted at $0 \cdot 1$ to $0 \cdot 15 \mathrm{M}-\left(\mathrm{NH}_{4}\right)_{2} \mathrm{CO}_{3}$ from Sephadex A-50 (Fig. 4). All of the toxicity was associated with this fraction. Repeated SDS-gel electrophoresis of the material in the major band showed that it contained only one polypeptide (Fig. 5) which moved with bovine serum albumin.

The molecular weight estimated from SDS-gel electrophoresis (about 70000) was confirmed by elution of the purified toxin from Sephadex G-100 in $1 \mathrm{~mm}-\mathrm{NaHCO}_{3}$ and comparison with elution volumes of proteins with known molecular weights. A single major peak with associated toxic activity was also found when the material in peak II from Sephadex G-200 chromatography was eluted from DEAE-cellulose using a similar gradient of $\left(\mathrm{NH}_{4}\right)_{2} \mathrm{CO}_{3}$ concentration and, subsequently, this latter method was used routinely to prepare purified toxin. The overall recovery was $20 \%$ of the initial protein in the crystal solution (Table 1) and the specific toxic activity was fourfold greater when expressed as toxic units (mg protein) ${ }^{-1}$. 


\section{Table 1. Purification of the toxic component of the crystals of Bacillus thuringiensis S-9}

Crystals were dissolved in reducing buffer $\left(10 \mathrm{mg} \mathrm{ml}^{-1}\right)$, dialysed against $1 \mathrm{~mm}-\mathrm{NaHCO}_{3}$ and incubated with trypsin $\left(0.5 \mathrm{mg} \mathrm{ml}^{-1}\right)$ at $18{ }^{\circ} \mathrm{C}$ for $3 \mathrm{~h}$. The toxin was purified from the digest by gel- and ion exchange-chromatography using the procedures detailed in Methods.

\begin{tabular}{|c|c|c|c|c|}
\hline & $\begin{array}{l}\text { Total } \\
\text { protein } \\
\text { (mg) }\end{array}$ & $\begin{array}{c}\text { Recovery } \\
\text { of protein }(\%)\end{array}$ & $\begin{array}{c}\text { Toxicity } \\
\text { [units (mg } \\
\text { protein) })^{-1} \text { ] }\end{array}$ & $\begin{array}{l}\text { Toxic } \\
\text { units } \\
\text { recovered } *\end{array}$ \\
\hline S-9 crystal solution & 175 & 100 & $10^{5}$ & $1.7 \times 10^{7}$ \\
\hline Trypsin digest of crystal solution & 175 & 100 & $6.6 \times 10^{4}$ & $1 \cdot 2 \times 10^{7}$ \\
\hline $\begin{array}{l}\text { Sephadex G-200 chromatography } \\
\text { (peak II) }\end{array}$ & 39 & 22 & $1.6 \times 10^{5}$ & $6 \cdot 2 \times 10^{6}$ \\
\hline $\begin{array}{l}\text { DEAE-cellulose chromatography of } \\
\text { peak II from Sephadex G-200 } \\
\text { (purified toxin) }\end{array}$ & 35 & 20 & $4 \times 10^{5}$ & $1.4 \times 10^{7}$ \\
\hline
\end{tabular}

* Corrected to allow for losses in volume due to sampling for bioassays, etc.

Purification of the proteolytic digest from serotypes 1 and 3 was carried out by chromatography on Sephadex G-200 and DEAE-cellulose. The elution patterns were similar to those described for the purification of toxin from serotype 9 and resulted in isolation of a single polypeptide from serotype 3 , as with serotype 9 (Fig. 2). However, the two polypeptides found in the digest of solutions of crystals from serotype 1 were not resolved.

\section{Amino acid analyses}

The amino acid compositions of crystals from all four strains were similar to one another (results not shown) and to previously published analyses (Cooksey, 1971). Amino acid analyses of the purified toxin from crystals of serotypes 3 and 9 and the purified fraction from serotype 1 were also similar to one another and to the analyses of crystals, although differing consistently from the latter in their content of glycine, phenylalanine and tyrosine.

Visual examination of two-dimensional chromatograms of the DNP-derivatives of $\mathrm{N}$ terminal amino acids in solutions of crystals revealed a pattern of six major spots that was similar for each of the four strains. For two strains (serotypes 3 and 9), quantitative estimation of the DNP-amino acids identified serine, glycine, lysine, glutamic acid, tryptophan and phenylalanine in the approximate molar ratio $6: 3: 1: 1: 1: 1$. For each strain, the major $N$-terminal amino acids were serine and glycine and these $N$-terminal amino acids were also identified when solutions of serotype 3 were examined by the Edman technique.

SDS-gel electrophoresis of solutions of crystals of serotype 3 prepared with reducing buffer at $\mathrm{pH} 10 \cdot 2$, urea/mercaptoethanol, alkali, or 6 M-guanidine at $\mathrm{pH} 7$ (Glatron et al., 1969) resulted in the same pattern in each case, and with one strain (serotype 3) the $\mathrm{N}$ terminal amino acids were found to be the same in preparations dissolved in reducing buffer, alkali and urea/mercaptoethanol. The only $N$-terminal amino acid found by the Sanger procedure in the purified toxin from serotypes 3 and 9 was serine: threonine was also found in the preparation from serotype 1 in amounts approximately equivalent to that of $\mathrm{N}$-terminal serine.

A preliminary characterization of the amino acids released by digestion of the purified toxin of serotype 9 with carboxypeptidase $A$ indicated that lysine was the first amino acid released with a probable $C$-terminal sequence-Phe-Tyr-Ser-Lys. With serotype 1 , lysine and serine were once again detected immediately after addition of the enzyme. However, other amino acids were detected in addition to those found with serotype 9 , indicating that more $C$-termini are present in the purified toxin from serotype 1 than in the purified toxin from serotype 9. 
Table 2. Toxicity of purified toxin of Bacillus thuringiensis S-9 to Pieris brassicae larvae by injection and ingestion

The inhibition of feeding $\mathrm{cf}$ larvae of Pieris brassicae was measured after injection $(5 \mu 1)$ or ingestion $(0.5 \mathrm{~cm}$ leaf disc coated with toxin) of the indicated dose of purified toxin.

\begin{tabular}{ccccc} 
Mose & \multicolumn{2}{c}{ Injection } & \multicolumn{2}{c}{ Ingestion } \\
$(\mu \mathrm{g})$ & $\begin{array}{c}\text { Mortality } \\
(\%)\end{array}$ & $\begin{array}{c}\text { Inhition of } \\
\text { leaf feeding } \\
(\%)\end{array}$ & $\begin{array}{c}\text { Mortality } \\
(\%)\end{array}$ & $\begin{array}{c}\text { Inhibition of } \\
\text { leaf feeding } \\
(\%)\end{array}$ \\
$2 \cdot 0$ & 100 & 100 & 100 & 100 \\
$1 \cdot 0$ & 100 & 100 & 100 & 100 \\
$0 \cdot 5$ & 86 & 85 & 80 & 70 \\
$0 \cdot 25$ & 58 & 80 & 70 & 70 \\
$0 \cdot 125$ & 30 & 40 & 50 & 40 \\
$0 \cdot 06$ & 33 & 0 & 40 & 20 \\
$0 \cdot 03$ & 16 & 0 & 20 & 0 \\
$0 \cdot 01$ & 2 & 0 & 0 & 0 \\
Control & 20 & 0 & 0 & 0
\end{tabular}

Immunological comparison of crystal solutions and purified fractions

Antisera were obtained to solutions of crystals of serotypes 1, 3 and 9. Using immunodoublediffusion in agar, crystal solution from serotype 2 did not show precipitin bands with any of the antisera. Crystal solutions from serotypes 1, 3 and 9 reacted with antisera to crystal solution from serotype 1 and serotype 3 to give two homologous precipitin bands. However, crystal solutions from serotypes 1 and 3 showed only partial homology with the solution from serotype 9 using antisera to crystals from serotype 9.

A quantitative precipitation reaction with serotype 2 crystal solution was detected using ${ }^{125}$ I-labelled antiserum; the precipitation reaction was weaker with crystal solutions from the other strains.

Rabbit antiserum to the purified toxin from serotype 9 was also obtained and gave a single homologous band against crystal solutions from serotypes 1, 3 and 9. Purified toxin preparations from serotype 1 did not react strongly although the preparations from serotypes 3 and 9 gave homologous bands with one another and with the single precipitin band formed with crystal solution. A single band, homologous with the above band, was also produced by immunodiffusion of crystal solution with antiserum prepared using toxin purified directly from crystal solution by ion-exchange chromatography (Herbert et al., 1971).

\section{Toxicity to lepidopterous larvae}

The $\mathrm{LC}_{50}$ values for crystal solutions of serotypes 1, 2, 3, and 9 with Plutella maculipennis were, respectively, $0.05,4 \cdot 00,0.5$ and $0.1 \mu \mathrm{g} \mathrm{ml}^{-1}$, and for serotypes 1,3 and 9 with Pieris brassicae were $0 \cdot 25,0 \cdot 1$ and $0 \cdot 15 \mu \mathrm{g} \mathrm{ml}^{-1}$. The purified proteins from serotypes 1,3 and 9 were also highly toxic to Pieris brassicae, although the specific activities were lower than those of undigested crystal solutions. This could have arisen from partial destruction of activity during purification and storage prior to bioassay, although dialysed crystal solutions were found to retain their toxicity in full for at least $70 \mathrm{~d}$ if stored at $0{ }^{\circ} \mathrm{C}$. The toxicity of each of the crystal solutions (serotypes 1, 3 and 9) was lowered to some extent by incubation with antisera either to the purified toxin or to crystal solution from serotype 9 .

The purified toxin from serotype 9 was toxic by injection (Table 2) as well as by ingestion. The dose for $50 \%$ inhibition of feeding by Pieris brassicae was in the range 0.06 to $0.25 \mu \mathrm{g}$ larva $^{-1}$. A bioassay of the injection toxicity of crystal solution was carried out simultaneously and, although results were limited to three concentrations, the toxicity $\left(\mathrm{LD}_{50}\right)$ of the crystal solution was in the same range $\left(0.01\right.$ to $\left.1.0 \mu \mathrm{g} \mathrm{larva}^{-1}\right)$ as that of the purified toxin $(0.06$ to $\left.0 \cdot 25 \mu \mathrm{g} \mathrm{larva}^{-1}\right)$. 


\section{DISCUSSION}

The Bacillus thuringiensis group of bacteria has been divided into at least 11 serotypes on the basis of serological characteristics (de Barjac \& Bonnefoi, 1968; de Barjac \& Thompson, 1970). Serotype 1 includes the original type-strain; strains of serotypes 3 and 9 have been widely used in other studies and serotype 2 is possibly the most extraordinary strain in that it differs in the mode of formation of the inclusion (Somerville et al., 1972). It seems reasonable to assume that the four strains selected for this study form a representative crosssection of the group.

The results of preliminary $N$-terminal analyses, which indicate that several polypeptide constituents are present in similar proportions in crystals from different strains, differ from those obtained by Glatron et al. (1969) who found only $N$-terminal phenylalanine in preparations of crystals dissolved in urea/guanidine at $\mathrm{pH} 7 \cdot 0$. From these and other studies of the $C$-terminal amino acids, these investigators concluded that a single polypeptide was present. In a single experiment using the conditions of Glatron et al., we have found a single spot corresponding to DNP-phenylalanine but in a much lower yield than any one of the DNP-amino acids found using the procedure described in Methods. Our tentative conclusion that the crystal contains a number of polypeptides is supported by the demonstration of multiple $N$-termini and by the results of SDS-gel electrophoresis, which indicate about six separate components (Figs 1 and 5).

In the present work, a purified toxin has been isolated from serotypes 3 and 9 ; it has a molecular weight of about 70000 as determined by gel chromatography and by gel electrophoresis. Herbert et al. (1971) determined a molecular weight of 55000 by gel electrophoresis for a toxin which they isolated by ion-exchange chromatography of dissolved crystals of serotype 9 . The low yield obtained by direct chromatography may be explained by the aggregation of crystal polypeptides in solution (Delafield et al., 1968). The purified toxin described in this paper could arise as a result of digestion of all other components of the crystal leaving an unaltered toxin, or as a result of proteolytic cleavage of a component of higher molecular weight. The $C$-terminal amino acid, lysine, is consistent with tryptic cleavage. However, the purified toxin reacts with antiserum to the toxin of Herbert and co-workers, has the same $N$-terminal amino acid as one of the crystal components and is unaltered during digestion as indicated by SDS-gel electrophoresis and densitometer scans of equivalent amounts of material during digestion (Fig. 1). These observations in dicate that the toxin is an unaltered component of the crystal, although $C$-terminal cleavage of a fragment cannot be excluded. As the purified toxin accounted for all of the toxicity originally present in crystal solutions, it can be concluded that only one of the polypeptides in the crystal is toxic in vivo.

The purified toxin is active both by ingestion and by injection, and as no activity was found with fragments of lower molecular weight, this suggests that further breakdown is not essential for activation of the toxin and that destruction of the midgut may not be the primary mode of action of the toxin. A comparative study of the initial effects of ingested and injected toxin might point to the site of action of this important toxin.

With serotype 1, the same purification procedure resulted in the isolation of a fraction which contained two polypeptides, as indicated by the presence of two bands on gel electrophoresis and by two $N$-termini. Gel electrophoresis indicated similar molecular weights (about 70000) for both bands, only one of which corresponded to a band in the undigested crystal solution (Fig. 2). One of the $\mathrm{N}$-termini, threonine, was not present in undigested solutions of crystals, suggesting that one of the polypeptides may have arisen from proteolysis of a larger polypeptide.

The difference in the immunological behaviour of the purified fraction from serotype 1 could arise from minor differences in the toxic polypeptide and also from the presence of a second polypeptide formed by digestion as suggested above, which could affect the immuno- 
logical properties in purified preparations. Despite this difference, the overall similarities in immunological, toxicological and biochemical properties, coupled with the more detailed work on purified toxin from serotype 9 suggest that the strains share a common toxin with a molecular weight of 70000 . Differences in insecticidal activity from strain to strain may arise from minor differences in the crystal and associated toxin; other factors such as spore toxins, haemolysins, immune system inhibitors, etc. (Somerville, 1977) are also likely to contribute to the variation in insecticidal activity between individual isolates of B. thuringiensis.

M. L. would like to acknowledge receipt of a S.R.C. CASE studentship. The assistance of colleagues at Shell Research Ltd with provision of insects, analyses, etc. and discussion with Dr I. R. Pendleton are also acknowledged. We thank Dr B. N. Herbert for the gift of antiserum.

\section{REFERENCES}

ANDREws, P. (1965). The gel filtration behaviour of proteins related to their molecular weight over a wide range. Biochemical Journal 96, 595-606.

DE BARJAC, H. \& BonNeFoI, A. (1968). Classification des souches de Bacillus thuringiensis. Comptes rendus hebdomadaire des séances de l'Académie des sciences 264, 1811-1813.

DE BARJAC, H. \& Thompson, J. V. (1970). A new serotype of Bacillus thuringiensis: $B$. thuringiensis var. thompsonii (serotype 11). Journal of Invertebrate Pathology 15, 141-144.

Bond, R. P. M., Boyce, C. B. C., Rogoff, M. H. \& SHIEH, T. P. (1971). The thermostable exotoxin of Bacillus thuringiensis. In Microbial Control of Insects and Mites, pp. 275-303. Edited by H. D. Burges \& N.W. Hussey. London: Academic Press.

CoOKSEy, K. E. (1971). The protein crystal toxin of Bacillus thuringiensis. Biochemistry and mode of action. In Microbial Control of Insects and Mites, pp. 247-274. Edited by H. D. Burges \& N.W. Hussey. London: Academic Press.

Delafield, F. P., Somerville, H. J. \& Rittenberg, S. C. (1968). Immunological homology between crystals and spores of Bacillus thuringiensis. Journal of Bacteriology 96, 713-720.

Edman, P. \& SJoquist, J. (1956). Identification and semiquantitative determination of phenyl thiohydantoins. Acta chemica scandinavica 10, 10-11.

Ellis, D. A. (1961). A new universal buffer. Nature, London 191, 1099.

Freedman, M. H., Slobin, L. I., Robbins, J. B. \& Sela, M. (1966). Soluble antigen-antibody complexes and intermediates in the purification of antibodies in $8 \mathrm{M}$ urea. Archives of Biochemistry and Biophysics 116, 82-91.

Galowalia, M. M. S., Gibson, N. H. E. \& Wolf, J. (1973). The comparative potencies of the crystalline endotoxin of $\mathrm{e}$. " $\mathrm{t}$ varieties of Bacillus thuringiensis to larvae or Pieris brassicae. Journal of Invertebrate Pathology 21, 301-308.

Glatron, M. F., Lecadet, M. M. \& Dedonder, R. (1969). Etude de la dissolution du cristal de Bacillus thuringiensis par ultracentrifugation et identification des extrémités $\mathrm{N}$ et $\mathrm{C}$ terminales.
Comptes rendus hebdomadaire des séances de l'Académie des sciences 269, 1338-1341.

Grant, G. F. \& Simon, M. (1968). Use of radioactive antibodies for characterizing antigens and applications to the study of flagella synthesis. Journal of Bacteriology 95, 81-86.

Herbert, B. N., Gould, H. J. \& Chain, E. B. (1971) Crystal protein of Bacillus thuringiensis var. tolworth. Sub-unit structure and toxicity of Pieris brassicae. European Journal of Biochemistry 24, 366-375.

KRYWienczyK, J. \& Angus, T. A. (1966). Serological studies of the protein parasporal inclusions of Bacillus thuringiensis var. entomocidus. Journal of Invertebrate Pathology 8, 439-441.

NorRIs, J. R. (1969). Macromolecule synthesis during sporulation of Bacillus thuringiensis. In Spores IV, pp. 45-58. Edited by L. L. Campbell. Bethesda: American Society for Microbiology.

Pendleton, I. R. \& Morrison, R. B. (1967). Analysis of the crystal antigens of Bacillus thuringiensis by gel diffusion. Journal of Applied Bacteriology 29, 519-528.

SANGER, F. (1949). Fractionation of oxidized insulin Biochemical Journal 44, 126-128.

Shapiro, A. L., Viñuela, E. \& Maizel, J. V. (1967). Molecular weight estimation of polypeptide chains by electrophoresis in SDS-polyacrylamide gels. Biochemical and Biophysical Research Communications 28, 815-820.

Somerville, H. J. (1973). Microbial toxins. Annals of the New York Academy of Sciences 217, 93-108.

Somerville, H. J. (1977). The insecticidal toxin of Bacillus thuringiensis. Proceedings Vatican Academy of Sciences, Study Week 14, 1976, Natural Products and the Protection of Plants, pp. 253-274.

Somerville, H. J. \& JoNes, M. L. (1972). DNA competition studies within the Bacillus cereus group of bacilli. Journal of General Microbiology 73, 257-263.

Somerville, H. J., TANada, Y. \& OMI, E. M. (1970). Lethal effect of purified spore and crystalline endotoxin preparations of Bacillus thuringiensis on several lepidopterous insects. Journal of Invertebrate Pathology 16, 241-248. 
Somerville, H. J., JAmes, C. R., Ruffell, R. N. \& NorRIs, J. R. (1972). The parasporal inclusion of Bacillus finitimus. Spore Research 1971, pp. 193200. Edited by A. N. Barker, G. W. Gould \& J. Wolf. London: Academic Press.

WeBER, K. \& Osborne, M. (1969). The reliability of molecular weight determinations by dodecyl sulfate-polyacrylamide gel electrophoresis. Journal of Biological Chemistry 244, 4406-4412.

Young, I. E. \& Fitz-James, P. C. (1959). Chemical and morphological studies of bacterial spore formation. II. Spore and parasporal formation in Bacillus cereus var. alesti. Journal of Biophysical and Biochemical Cytology 6, 483-498. 